\title{
Generalizability of a Measure of Visitor Satisfaction with Outdoor Recreation
}

\author{
John H. Schomaker and Richard C. Knop: \\ USDA Forest Service, North Central Forest Experiment Station
}

\begin{abstract}
A measure of visitor satisfaction with outdoor recreation is important for effective management. Cronbach's theory of generalizability was used to estimate the effects of time of measurement, item
\end{abstract}

\begin{abstract}
context, and item content on a recreation satisfaction measure, which was given to floaters on two rivers. The influences of item content, item context, and times were large, small, and none, respectively.
\end{abstract}

A measure of satisfaction is important to providers of outdoor recreation because it helps them monitor the quality of services provided. Visitor satisfaction has thus emerged as a central variable in the study of outdoor recreation behavior.

Several researchers have attempted to measure visitor satisfaction, usually by one of the following three methods: global evaluation (Foster \& Jackson, 1979; Heberlein \& Vaske, 1977; Heywood, 1975; Peterson, 1971; Roggenbuck \& Schreyer, 1977; Schreyer, Roggenbuck, McCool, Roger, \& Miller, 1976; Shelby, 1980; Trafton \& Tinsley, 1980), multiple dimensions (Beard \& Ragheb, 1980; London, Crandall, \& Seals, 1977; Pierce, 1980; Potter, Hendee, \& Clark, 1973; Stankey \& Lucas, 1973), and composite measures (Dorfman, 1979; Hawes, 1978; Peterson, 1974; Sobel \& McGuire, 1977). The important issue of measurement reliability, however, has not been adequately addressed. The purpose of the present study was, therefore, to evaluate the extent to which time, context, item, and setting variables introduce error into the measurement of visitor satisfaction.

Time. Time was a variable of interest because most outdoor recreation research relies heavily on mail questionnaires. This reflects a desire to minimize interruptions of the recreation experience. Weeks or even months can pass between the experience and completion of the questionnaire.

Context. Several researchers have established that the context of questions surrounding a subjective measure affects response (Anderson, 1975; Duncan \& Schuman, 1980; Marsh \& Parducci, 1978; McGarvey, 1943; Parducci, 1968).For example, in Parducci's (1968) study of moral judgments, "Poisoning a neighbor's dog whose barking bothers you" was rated more negatively when accompanied by a list of less serious actions, such as "Keeping a dime you find in a telephone booth," than when accompanied by more serious items, such as "Murdering your mother without justification or provocation." Recreation researchers tend not to use the same questionnaire from study to study. For

APPLIED PSYCHOLOGICAL MEASUREMENT

Vol. 6. No. 2, Spring 1982, pp. 173-183

(C) Copyright 1982 Applied Psychological Measurement Inc.

$0146-6216 / 82 / 020173-1181.55$ 
example, the same measure of satisfaction might be used in questionnaires for wilderness users in the East and West, but the questionnaires might otherwise differ markedly. When such comparisons of satisfaction are made, researchers need to make certain that the differences in satisfaction scores are caused by real differences between populations rather than question context.

Item. Item effects were of interest because a uniform measure of satisfaction has not been adopted by recreation researchers. Many different wordings of items are currently used to assess satisfaction. It is important then to know to what extent satisfaction scores depend on the particular items chosen to comprise the scale.

Setting. Because the purpose of the satisfaction measure is to distinguish among different recreation locales in terms of their performance, an effective satisfaction measure would have its variability be more attributable to differences in recreation setting than to differences in time, context, and item. By explicitly considering setting effects, this desirable trait was tested.

\section{Study Overview}

An ongoing national river survey, conducted by the USDA Forest Service, served as the framework for the present study. A six-item, Likert-type satisfaction measure was developed for and included as a standard feature of the survey.

Data analysis in the present study was guided by Cronbach's theory of generalizability (Cronbach, Gleser, Nanda, \& Rajaratnam, 1972). Consistent with Cronbach's terminology, the sources of variation in satisfaction-time, context, item, setting-will be referred to here as facets, and a particular level within each facet will be called a condition. Cronbach's approach was chosen because it explicitly considers the facets and their interactions, and it can be used to estimate the reliability of studies having different designs (Gleser, Cronbach, \& Rajaratnam, 1965).

\section{Methed}

\section{Satisfinction Mensure}

The satisfaction scale was developed and refined through pretesting of a 15 -item inventory on a sample of 1,000 river users in 1977. The scale taps five satisfaction concepts developed in the job, consumer, recreation, and quality-of-life fields. The six Likert-type items are combined to provide a composite measure of overall satisfaction (Locker \& Dunt, 1978). The concepts and their related items are as follows:

Concept Item

General Enjoyment

"I thoroughly enjoyed the trip."

Comparison with an Ideal

Equitable Fulfillment

"I cannot imagine a better river trip."

Behavioral Intention

"The river trip was well worth the money I spent to take it."

"I do not want to run any more rivers like this one" and "I want to go back and run that river again."

Dissatisfaction

"I was disappointed with some aspects of my trip."

The response format was a five-point "strongly disagree" to "strongly agree" scale scored from -2 to +2 .

Farets

To test the setting effect, the satisfaction measure was administered to samples of recreationists 
from two different rivers, the Upper Delaware in New York and the Ocoee in Tennessee. These two rivers differ greatly in the setting and recreational opportunities they offer.

To test the effect of time, questionnaires containing the satisfaction measures were mailed to a sample of recreationists from the rivers at two different times. For Time $1\left(T_{1}\right)$, questionnaires containing the satisfaction items were mailed in September 1979, soon after the summer trips. For Time $2\left(T_{2}\right)$, questionnaires were sent in January 1980 , approximately 5 months after the summer use season. The number of days between the river trip and the return of the questionnaire for $\mathbb{T}_{1}$ ranged from 43 to 130 , with an average of 72 ; and from 127 to 263 for $T_{2}$, with an average of 184 .

To test the context effect, three distinct questionnaires were used. One questionnaire, designated as "full" context, was used in the ongoing nationwide survey of river recreation urse ( $K$ nopf \& Lime, in press). The satisfaction items were intermingled with 10 other items in a section approximately twothirds of the way through the questionnaire.

The second questionnaire, designated as "partial" context, consisted wholly of the 16 items containing the satisfaction items from the full questionnaire. The nonsatisfaction items tapped the respondent's reaction to wildlife, the job being done by managers, the number and actions of other people, and the character of the river and landscape.

The third questionnaire consisted solely of the six satisfaction items and was designated as "absent" context. In the "partial" and "absent" contexts, two nonevaluation items preceded the question containing the satisfaction items. These items dealt with the type of group the respondent traveled with and the respondent's previous experience on the river. The items were used to check for sampling bias and to lessen first-item response bias for the question containing the satisfaction item (Dillman, 1978).

\section{Dåigin}

In order to capitalize on existing data from the nationwide study, facet effects were studied through two analyses. One analysis focused on the effects of time, the other on the effects of items, context, and setting. Figure 1 a represents data available from the nationwide study; Figure $1 \mathrm{~b}$ represents data gathered specifically for the generalizability study.

The analysis that focused on the effects of time used data represented by the shaded blocks in Figures $1 \mathrm{a}$ and $1 \mathrm{~b}$. In this portion of the study, a single form of the questionnaire was used, and all subjects $(S)$ responded to the same items $(D)$. Thus, subjects were nested within each river-time $(R-T)$ combination $(\mathbb{I} \times(S: R \times \mathbb{T}))$.

The analysis that focused on the effects of item, context (C), and river used data represented by Figure $1 \mathrm{~b}$. A single time was used, all subjects responded to the same items, and subjects were nested within each river-context $(\mathbb{R}-C)$ combination $(I \times(S: \mathbb{R} \times C))$.

\section{Sample}

Names and addresses were obtained from a representative sample of persons floating the Ocoee and Upper Delaware Rivers during the summer use season of 1979. As part of the nationwide survey, questionnaires were sent to 350 persons randomly chosen from the sample pool from each river. In January a new sample of 1,050 people was drawn for each river with each of the three questionnaire contexts going to 350 persons on each river. The September mailing produced 153 returns for the Ocoee and 109 returns for the Upper Delaware. Response to the January mailing ranged from 157 for the Upper Delaware visitors who were sent the full-context questionnaire to 226 for the Ocoee visitors 


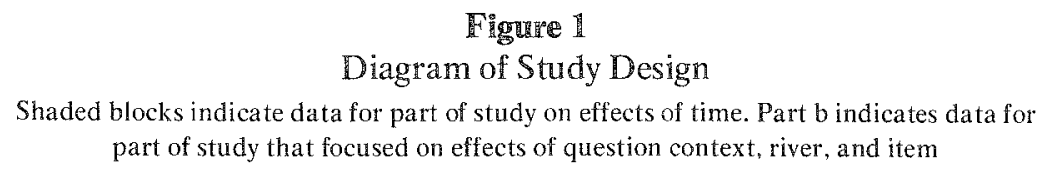

TIME 1

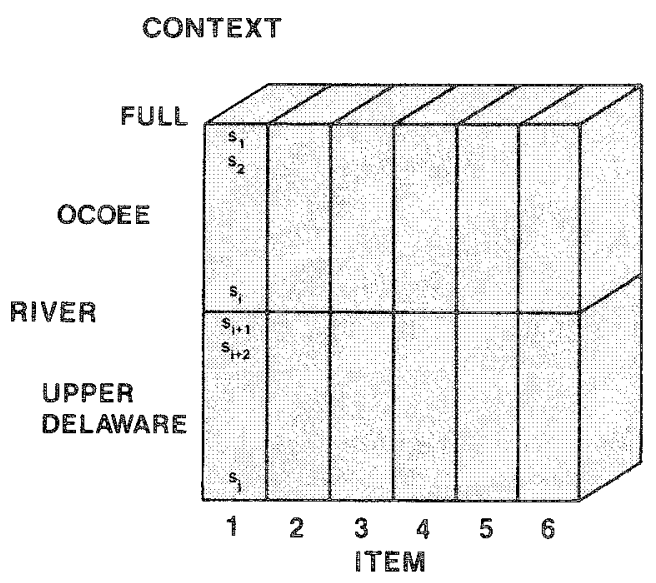

(A)
THPE 2

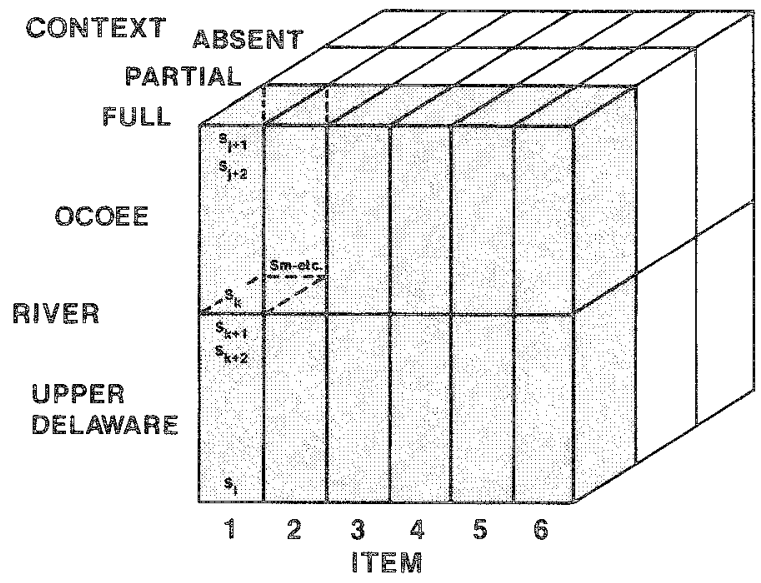

(B)

who were sent the absent-context questionnaire. To provide for an equal number of cell sizes during analysis, cases were randomly deleted until all classifications had the same number of observations. This gave four groups of 109 each for the time portion of the study and six groups of 157 each for the item, context, and setting portion of the study.

\section{Analysis}

The theory of generalizability was used to isolate the contribution of time, item, context, and river to the variance of the obtained satisfaction scores. The test conditions were treated as a random sample of all possible measurement conditions. Separate analyses were performed for the parts of the study represented by the shaded portions of Figures $1 \mathrm{a}$ and $1 \mathrm{~b}$. Because the partition of variance depends on the study design, it was not possible to isolate the contribution of subjects and interactions involving subjects to satisfaction score variance. Because the designs were relatively complex, the sums of squares were calculated as if the sources were crossed and then accumulated according to the actual nested design (Cronbach et al. , 1972, p. 45).

The satisfaction measure was treated as the mean value for the six items, and the variance components were estimated accordingly. The variance component for a facet represents the variance over all admissible conditions for that facet. The expected mean square (EMS) for a particular source of variance is the weighted sum of variance components for the facets and for their interactions (Cronbach et al., 1972, p. 43). Because the conditions of measurement were assumed to be randomly sampled, the observed mean squares from the analysis of variance were considered estimates of expected mean squares.

The formulas used to calculate the components of variance for the part of the study represented in Figure $1 \mathrm{~b}$ are shown in Equations 1 through 9, where $\sigma^{2}$ is variance and $e=$ error, $c=$ context, 
$i=$ item, $r=$ river, $s=$ subjects, and $\eta$ is the number of conditions for a particular facet. Thus, $\sigma_{c}^{2}$ is the variance component for context and $\sigma_{c r i}^{2}$ is variance for the interaction of contexts, rivers, and items.

$$
\begin{aligned}
& \mathrm{EMS}_{\text {residual }}=\sigma_{\mathrm{e}}^{2} \\
& \mathrm{EMS}_{\mathrm{cri}}=\sigma_{e}^{2}+\eta_{\mathrm{s}} \sigma_{\text {cri }}^{2} \\
& \text { EMS } s, c s, r s, \operatorname{crs}=\sigma_{e}^{2}+\eta_{i} \sigma_{s, c s,}^{2}, r s, \text { crs } \\
& \mathrm{EMS}_{\mathrm{cr}}=\sigma_{\mathrm{e}}^{2}+\eta_{\mathrm{s}} \sigma_{\mathrm{cri}}^{2}+\eta_{i} \sigma_{\mathrm{s}, \mathrm{cs}, \mathrm{rs}, \mathrm{crs}}^{2}+\eta_{\mathrm{s}} \eta_{i} \sigma_{\mathrm{cr}}^{2} \\
& \text { EMS }{ }_{c i}=\sigma_{e}^{2}+\eta_{s} \sigma_{c r i}^{2}+\eta_{s} \eta_{r} \sigma_{c i}^{2} \\
& \text { EMS }_{\text {ir }}=\sigma_{e}^{2}+n_{s} \sigma_{c r i}^{2}+n_{s} n_{c} \sigma_{i r}^{2} \\
& \mathrm{EMS}_{r}=\sigma_{e}^{2}+\eta_{s} \sigma_{\mathrm{cri}}^{2}+n_{i} \sigma_{s, c s, r s, \operatorname{crs}}^{2}+n_{s} n_{i} \sigma_{c r}^{2}+ \\
& \eta_{s} \eta_{c} \sigma_{i r}^{2}+\eta_{s} \eta_{i} \eta_{c} \sigma_{r}^{2} \\
& \text { EMS } i=\sigma_{e}^{2}+\eta_{s} \sigma_{c r i}^{2}+\eta_{s} \eta_{r} \sigma_{c i}^{2}+\eta_{s} \eta_{c} \sigma_{i r}^{2}+\eta_{s} \eta_{c} \eta_{r} \sigma_{i}^{2} \\
& \operatorname{EMS}_{c}=\sigma_{e}^{2}+\eta_{s} \sigma_{c r i}{ }^{2}+\eta_{i} \sigma_{s}^{2}, c s, r s, c r s+\eta_{s} \eta_{r} \sigma_{c i}{ }^{2}+ \\
& \eta_{s} \eta_{i} \sigma_{c r}{ }^{2}+\eta_{s} \eta_{i} \eta_{r} \sigma_{c}^{2}
\end{aligned}
$$

The components of variance were calculated beginning with Equation 1 and successively solving for the one unknown quantity in the next equation. The weights for the components of variance in the above equations were the number of subjects, $n_{s}=157$; number of items, $n_{i}=6$; number of rivers, $n_{r}=2$; number of contexts, $n_{c}=3$. The equations for the part of the study represented in the shaded portions of Figure $1 \mathrm{a}$ and $1 \mathrm{~b}$ were analogous to Equations 1 through 9 with the substitution of time for context and appropriate adjustment of numbers, $n_{s}=109 ; n_{i}=6 ; n_{r}=2 ;$ number of times, $n_{t}=2$.

\section{Resulits}

The variance components associated with each facet are displayed in Tables 1 and 2 . Table 1 summarizes the analysis of the effect of Time, and Table 2 summarizes the effects of Context, Item, and River. Although both tables provide information about the River and Item effects, Table 2 will be used in the discussion of these effects because the estimates of variance in Table 2 are based on larger sample sizes. 
Table 1

Estimates of Variance Components from Generalizability Study with the Design Items $\times$ (Subjects: (Time $x$ River))

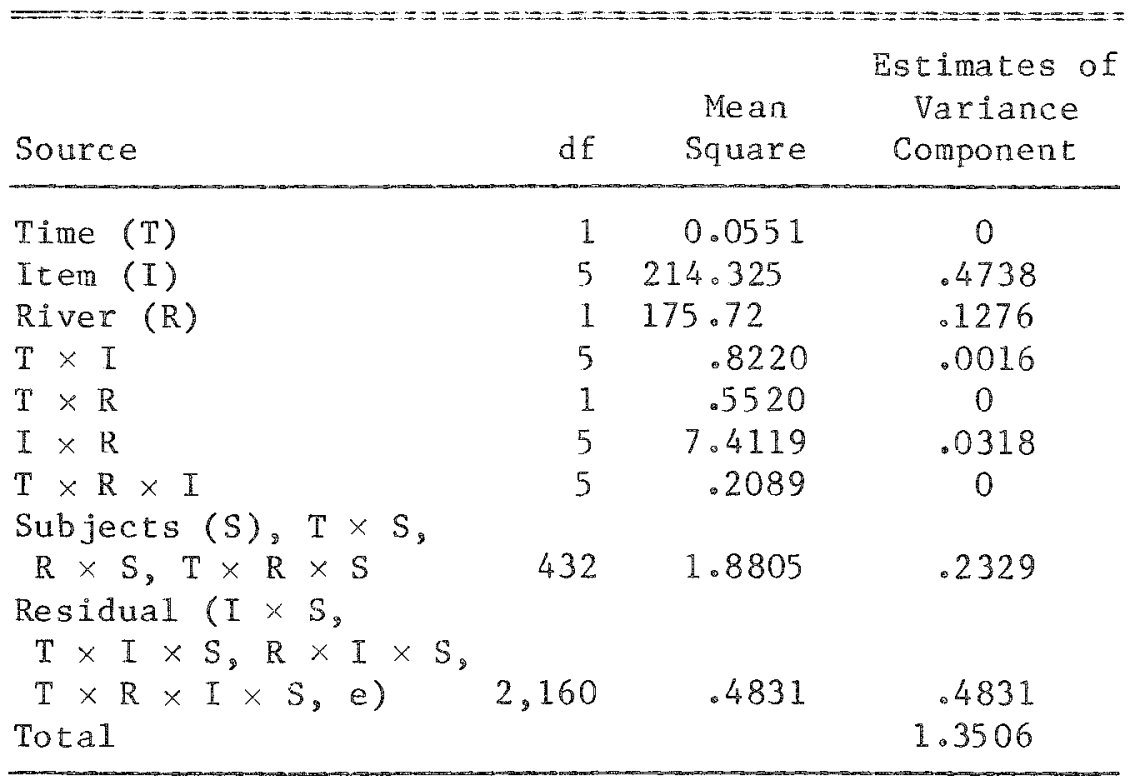

Table 2

Estimates of Variance Components from Generalizability Study with the Design Items $\times$ (Subjects: (Context $\times$ River $)$ )

\begin{tabular}{|c|c|c|c|}
\hline Source & $d f$ & $\begin{array}{l}\text { Mean } \\
\text { Square }\end{array}$ & $\begin{array}{l}\text { Estimates of } \\
\text { Variance } \\
\text { Component }\end{array}$ \\
\hline Context (C) & 2 & 16.1159 & .0065 \\
\hline Item (I) & 5 & 401.41 & .4083 \\
\hline River $(R)$ & 1 & 324.366 & .1090 \\
\hline $\mathrm{C} \times \mathrm{I}$ & 10 & 2.4378 & .0059 \\
\hline$C \times R$ & 2 & 1.4450 & 0 \\
\hline$I \times R$ & 5 & 14.9413 & .0305 \\
\hline$C \times R \times I$ & 10 & .5758 & .0006 \\
\hline $\begin{array}{l}\text { Subject }(S), C \times S \\
R \times S, C \times R \times S\end{array}$ & 936 & 1.9515 & .2459 \\
\hline $\begin{array}{l}\text { Residual }(I \times S, \\
C \times I \times S, R \times I \times S, \\
C \times R \times I \times S, e) \\
\text { Total }\end{array}$ & 4,680 & .4758 & $\begin{array}{r}.4758 \\
1.2825\end{array}$ \\
\hline
\end{tabular}


Of the facets considered in this study, the major sources of variance were associated with Item effects and River effects. Context contributed a small portion of variance, and Time contributed essentially none. Of the seven interactions tested, only the Item-by-River interaction contributed markedly to the variance. Subjects and interaction terms involving Subjects also accounted for a considerable proportion of variance. Lastly, residual sources contributed a large proportion of variance. The high residual arose from second-and higher-order interactions of Subjects and Items and from all the other possible conditions affecting measurement that were not specifically considered in this study.

\section{Discussion}

Varying periods of time between the recreation experience and measurement of satisfaction through mail questionnaires should cause little concern, judging from the small components of variance attributed to Time and interactions involving Time. However, this conclusion might not hold for time periods shorter than those studied here.

Consumer satisfaction researchers speculate that reported satisfaction increases with time (Miller, 1976). There is some evidence for this effect in recreation. Peterson and Lime (1973) found that canoeists were less negative in their attitude toward hardship factors (such as poorly maintained portages, cuts and blisters, and having to carry canoes) when contacted in their home after a trip than when contacted during their trip. This study suggests that most of this positive re-evaluation occurs before 10 weeks following a trip and that attitudes are relatively stable thereafter.

The large Item variance component indicates that response is linked to the nature of the item. For the part of the study represented by Figure $1 b$, average response ranged from 3.0 for "I cannot imagine a better river trip" to 4.7 for "I thoroughly enjoyed the trip." Thus, in comparing satisfaction scores, the same items must be used to maintain a constant measure. Even though the items have different averages, responses to the items generally vary together. For the 942 respondents represented in Figure $1 \mathrm{~b}$, the average inter-item correlation was .41 and coefficient alpha was .79 .

The Context facet was of particular interest. The nationwide study of river recreation users is expected to continue for several years. The satisfaction measure is expected to be retained as an integral component of the survey instrument, but it is likely that the overall composition of the questionnaire will change as old problems in river recreation management and research are solved and new ones arise. The reliability study gives some indication of how sensitive the satisfaction measure might be to these changes. The results are encouraging. The small Context variance component indicates that the context within which the satisfaction items are presented does not matter a great deal; the measured level of satisfaction will be about the same.

However, it would be a mistake to conclude that context is unimportant for all forms of analysis. As Rosenthal and Rubin (1979) have demonstrated, percent variance explained can be deceptive, and its interpretation is sensitive to the set of conditions surrounding use of the data. If all that is needed is a general index of how satisfied river recreationists are with a particular setting, then the effects of question context are not a great concern. If differences across river settings or over time must be detected, however, context can introduce troublesome error. It is rare in recreation research when crossresource or time-series analyses have constant question context. Populations that might otherwise be equal in satisfaction levels might differ significantly when evaluated by the same scale within different contexts. The difference could be attributed incorrectly to setting, while the real determinant was context.

The relatively large setting component of variance confirms that it is possible for some settings to produce more satisfaction, on the average, than others. This finding is most important for the concep- 
tual foundation, as opposed to the methodology, of the river research program. It is certain now that different rivers are capable of producing different levels of satisfaction.

Further insight into the factors influencing the satisfaction measures can be gained by examining the interaction components. Because the Context-by-River interaction was zero, it can be concluded that the measured level of satisfaction is not influenced by particular combinations of contexts and rivers. This result is surprising.

The usual effect of context is to lower ratings for a questionnaire item surrounded by others at the top end of the response range and to raise ratings for an item surrounded by items at the lower end (Parducci, 1968). It was expected that response to the satisfaction measure would be influenced by items requesting an evaluation of wildlife, wild country, rapids, scenery, and wilderness. Having people rate their trips along these attributes may have provided the description of an ideal river trip as a frame of reference and, consequently, lowered satisfaction judgments for a river trip that did not meet these ideal standards.

Because it was felt that the Upper Delaware trips fall further from the ideal than Ocoee trips, this context was expected to depress the satisfaction scores more on the Upper Delaware than on the Ocoee River. However, the small contributions to variance by the Context-by-Item and Context-byRiver-by-Item interactions help confirm the insensitivity of the satisfaction measure to context. The small variance component for Context-by-Item interaction indicates that only slightly different patterns of item responses arose from different contexts.

The Item-by-River interaction suggests that different rivers elicit different patterns of item responses. This is another indication that the same items should be used in a composite measure from setting to setting. Evidently, visitors on different rivers are emphasizing different concepts in their evaluations. As a result, rivers compared along the dimension of a single concept-equitable fulfillment, for example-might be ranked differently for different concepts of satisfaction. Because a broad interpretation of satisfaction is useful in river studies, it makes sense to adhere to a composite and to realize that each item is only tapping a part of the concept of satisfaction and that some variation exists in the internal interpretation of the measure from setting to setting.

A considerable proportion of the variance arose from subjects and interaction terms involving subjects. It is presumed that much of the variance reflects different levels of response among subjects. However, within the design used in this study, it was not possible to isolate contributions from this source. Data from a completely crossed design would be required to isolate the subject contribution and its interactions, and thus determine to what extent each person has a unique response and response pattern for each context, setting, and context-by-setting combination. A study with a crossed design, however, is not practical, because a person's river recreation experiences are widely separated in space and time; and it would be difficult to find a large enough sample of people who had experienced the same rivers. In any event, estimating each particular component of variance involving subjects is not crucial because the components are confounded in the actual designs used in most recreation studies.

The results of the analysis were used to estimate the coefficients of generalizability of the satisfaction measure, as routinely employed in the Forest Service river study where the same items will always be used. In Cronbach's terms, the discussion will turn from the G-study to the D-study (Cronbach et al., 1972, p. 17).

Generalizability is a function of (1) the sources of variance contributing error to the satisfaction measure and (2) the study design. Sources of variance in future studies include context, subject, and residual. Time will not be a source because its effect has been shown to be small. Item is removed as a source of error by considering items as fixed, rather than random. 
Because it is now desirable to consider the items as fixed, the components of variance established in the generalizability study must be recalculated. The components of variance for the random model were used in estimating the components for the mixed model (Cronbach et al., 1972, p. 61). The new components were $\sigma_{r \mid I}^{2}=.1141, \sigma_{c \mid I}^{2}=.0075, \sigma_{c r \mid I}^{2}=.0001$, and $\sigma_{s: c r \mid I}^{2}=.3252$, where $I$ emphasizes that items are fixed. The study design has subjects nested within contexts (a subject will respond to the satisfaction items in only one context), and contexts nested within rivers (a single context will be used for a particular river, but different contexts might be used on different rivers). This entire nesting is crossed with items (the same items are used independent of particular subject, context, and river combinations).

The estimated generalizability of satisfaction scores for the above conditions is a function of the number of subjects and is given by

$$
\begin{aligned}
\text { coefficient of generalizability }= & \sigma^{2} r \mid I\left(\sigma^{2} r \mid I+\sigma_{c \mid I}^{2}+\right. \\
& \sigma^{2}\left(r \mid I+\left(1 / n_{s}\right) \sigma_{s: c r \mid I}^{2}\right)
\end{aligned}
$$

The coefficient from Equation 10 indicates on a 0 to 1 scale how well an estimation of average satisfaction under a given set of time, context, and item conditions approximates the average satisfaction that would be determined under all combinations of time, context, and item conditions.

For the values generated in this study, the generalizability coefficient approaches a maximum of .94 as the number of subjects is increased. Having established the generalizability of the measure, the important issue is the number of people that need to be contacted on a river to obtain a good estimate of satisfaction levels. The coefficient was plotted against the number of subjects, and it was found that the coefficient is .89 with 50 subjects. Above 50 , the increase in generalizability is small for large increases in subject numbers. Thus, approximately 50 subjects will give a good estimate of the average visitor satisfaction for a river.

\section{Corrchlnsion}

The satisfaction scale introduced here is adaptable to other activities and settings by substituting the appropriate referent for "river" in selected items. A foundation has been provided that other researchers can use to evaluate the reliability of this measure when applied to other recreation activities. Within the limits of this study, it was learned that those using this scale need not be concerned with time of measurement. Also, item selection is important and relatively few visitors need to be contacted to get a good estimate of average satisfaction.

Recreation research needs to examine more carefully the extent to which satisfaction measures now routinely used are generalizable. In particular, there is a need to isolate sources of error so that they can be controlled. The theory of generalizability has been demonstrated to be useful for these purposes.

\section{References}

Anderson, N. H. On the role of context effects in psychological judgment. Psychological Review, 1975, $82,462-482$.

Beard, J. G., \& Ragheb, M. G. Measuring leisure satisfaction. Journal of Leisure Research, 1980, 12, $20-33$.
Cronbach, L. J., Gleser, G. C., Nanda, H., \& Rajaratnam, N. The dependability of behavioral measurements: Theory of generalizability for scores and profiles. New York: John Wiley $\&$ Sons, 1972. 
Dillman, D. A. Mail and telephone surveys-the total design method. New York: John Wiley \& Sons, 1978.

Dorfman, P. W. Measurement and meaning of recreation satisfaction. A case study in camping. Environment and Behavior, 1979, 11,483-510.

Duncan, O. D., \& Schuman, H. Effects of question wording and context: An experiment with religious indicators. Journal of the American Statistical Association. 1980, 75, 269-275.

Foster, R. J., \& Jackson, E. L. Factors associated with camping satisfaction in Alberta Provincial Park campgrounds. Journal of Leisure Research. 1979, 11, 292-306.

Gleser, G. C., Cronbach, L. J., \& Rajaratnam, N. Generalizability of scores influenced by multiple sources of variance. Psychometrika, 1965, 30, $395-418$.

Hawes, D. K. Satisfactions derived from leisure-time pursuits: An exploratory nationwide survey. Journal of Leisure Research, 1978, 10, 247-264.

Heberlein, T. A., \& Vaske, J. J. Crowding and visitor conflict on the Bois Brule River (Technical Report WIS WRC 77-04). Madison: University of Wisconsin, Water Resources Center, 1977.

Heywood, J. L. Group cohesiveness and satisfaction on Grand Canyon Colorado River raft trips. Unpublished doctoral dissertation, University of Arizona, 1975

Knopf, R. C., \& Lime, D. W. The national river recreation study: An aid to recreation management (Research Paper NC-222). St. Paul MN: U.S. Department of Agriculture, Forest Service, North Central Forest Experiment Station, in press.

Locker, D., \& Dunt, D. Theoretical and methodological issues in sociological studies of consumer satisfaction with medical care. Social Science and Medicine, 1978, 12, 283-292.

London, M., Crandall, R., \& Seals, G. W. The contribution of job and leisure satisfaction to quality of life. Joumal of Applied Psychology, 1977, 62, 328-334.

Marsh, H. W., \& Parducci, A. Natural anchoring at the neutral point of category rating scales. Journal of Experimental Social Psychology, 1978, 14. 193-204.

McGarvey, H. R. Anchoring effects in the absolute judgment of verbal materials. Archives of $P_{s y}$ chology, 1943, 39, No. 281.

Miller, J. A. Studying satisfaction, modifying models, eliciting expectations, posing problems, and making meaningful measurements. In $\mathrm{H}$. K. Hunt (Ed.), Conceptualization and measurement of consumer satisfaction and dissatisfaction. Cambridge MA: Marketing Science Institute, 1977.
Parducci, A. The relativism of absolute judgments. Scientific American, 1968, 219, 84-90.

Peterson, G. L. Motivations, perceptions, satisfactions and environmental dispositions of Boundary Waters Canoe Area users and managers (Final Report: Northwestern University and USDA Forest Service Cooperative Research Project 13-253). St. Paul MN: U.S. Department of Agriculture, Forest Service, North Central Forest Experiment Station, 1971.

Peterson, G. L. Evaluating the quality of the wilderness environment. Congruence between perception and aspiration. Environment and Behavior, $1974,6,169-193$.

Peterson, G. L., \& Lime, D. W. Two sources of bias in the measurement of human response to the wilderness environment. Journal of Leisure Research, $1973,5,66-73$.

Pierce, $\mathbb{R} . \mathbb{C}$. Dimensions of leisure. I: Satisfactions. Journal of Leisure Research. 1980, 12, 5-19.

Potter, D. R., Hendee, J. C., \& Clark, R. N. Hunting satisfaction: Games, guns, or nature? In Transactions of the 38th North American Wildlife and $\mathrm{Na}$ tural Resources conference. Washington DC: Wildlife Management Institute, 1973.

Roggenbuck, J. W., \& Schreyer, R. M. Relations between river trip motives and perception of crowding, management preference and experience satisfaction. In Proceedings of the River Recreation Management and Research Symposium (General Technical Report NC.28). St. Paul MN: U.S. Department of Agriculture, Forest Service, North Central Forest Experiment Station, 1977.

Rosenthal, R., \& Rubin, D. B. A note on percent variance explained as a measure of the importance of effects. Journal of Applied Social Psychology, $1979,9,395-396$

Schreyer, R., Roggenbuck, J. W., McCool, S. F., Roger, L. E., \& Miller, J. The Dinosaur National Monument whitewater river recreation study. Logan UT: Utah State University, Institute for the Study of Outdoor Recreation and Tourism, 1976.

Shelby, B. Crowding models for backcountry recreation. Land Economics, 1980, 56, 43-55.

Sobel, R. S., \& McGuire, H. Subtractive models of satisfaction: Cognitive processes or measurement artifact? Journal of Psychology, 1977, 96. 251-258.

Stankey, G. H., \& Lucas, R. C. Relationships between hunting success and satisfaction. In Transactions of the 38th North American Wildlife and Natural Resources Conference. Washington DC: Wildlife Management Institute, 1973.

Trafton, R. S., \& Tinsley, H. E. A. An investigation of the construct validity of measures of job, leisure 
(dyadic) and general life satisfaction. Journal of Leisure Research, 1980, 12, 34-44.

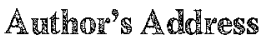

Send requests for reprints or further information to John H. Schomaker, USDA Forest Service, North Central Forest Experiment Station, 1992 Folwell Ave. nue, St. Paul MN 55108. 